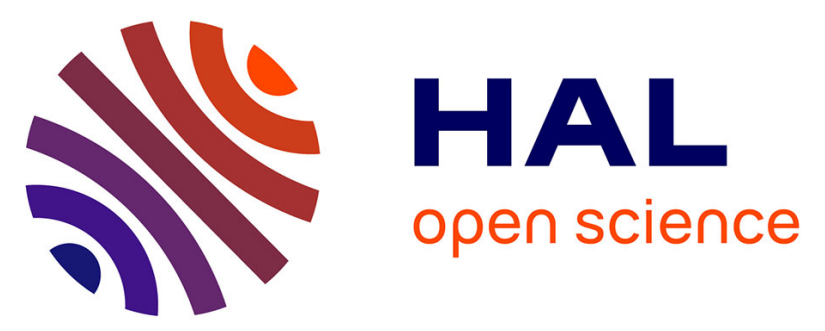

\title{
Is there a single non-painful procedure in the intensive care unit? It depends!
}

Gerald Chanques, Jean-Marc Delay, Océane Garnier, Jérome Berra, Albert Prades, Julie Carr, Audrey de Jong, Nicolas Molinari, Samir Jaber

\section{- To cite this version:}

Gerald Chanques, Jean-Marc Delay, Océane Garnier, Jérome Berra, Albert Prades, et al.. Is there a single non-painful procedure in the intensive care unit? It depends!. Intensive Care Medicine, 2018, 44 (4), pp.528 - 530. 10.1007/s00134-018-5051-x . hal-01786973

\section{HAL Id: hal-01786973 \\ https://hal.umontpellier.fr/hal-01786973}

Submitted on 8 Jan 2020

HAL is a multi-disciplinary open access archive for the deposit and dissemination of scientific research documents, whether they are published or not. The documents may come from teaching and research institutions in France or abroad, or from public or private research centers.
L'archive ouverte pluridisciplinaire HAL, est destinée au dépôt et à la diffusion de documents scientifiques de niveau recherche, publiés ou non, émanant des établissements d'enseignement et de recherche français ou étrangers, des laboratoires publics ou privés. 


\section{Is there a single non-painful procedure in the intensive care unit? It depends!}

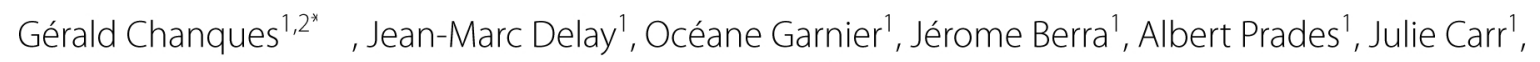
Audrey de Jong ${ }^{1,2}$, Nicolas Molinari ${ }^{2,3}$ and Samir Jaber ${ }^{1,2}$

\section{Dear Editor,}

Pain assessment is challenging in intensive care unit (ICU) patients if they are sedated or delirious, and often unable to communicate [1]. For these patients, behavioural pain tools are recommended to detect pain and adjust analgesics. Eight years ago, to validate the Behavioural Pain Scale (BPS) for non-intubated patients, we chose a catheter dressing change and turning a patient as the reference non-painful and painful procedures, respectively [2]. The BPS score did not significantly change during the dressing change, while it significantly increased when turning the patient, as expected. Recently, we performed an accuracy diagnosis study to validate the Analgesia Nociception Index (ANI). The ANI is an electrophysiological tool that measures pain intensity using spectral analysis of heart rate variability, allowing estimation of the balance between parasympathetic and sympathetic tones [3]. Unexpectedly, the BPS score significantly increased during the catheter dressing change, while ANI strongly decreased, indicating higher sympathetic tone. This was compatible with significant pain, as defined by a BPS $\geq 5$ [3]. This questions the nonpainful nature of our catheter dressing change procedure. Because the inclusion criteria required that the patients were unable to communicate, it was not possible to know whether the patients really experienced pain or not. To address this issue, we included 20 new consecutive ICU patients who were able to self-rate their pain intensity using a visually enlarged $0-10$ numeric rating scale (NRS) and who were not delirious (negative for the confusion assessment method for the ICU [4]). In addition

*Correspondence: g-chanques@chu-montpellier.fr

${ }^{1}$ Department of Anaesthesia and Critical Care Medicine, University of Montpellier Saint Eloi Hospital, 34295 Montpellier Cedex 5, France Full author information is available at the end of the article to the NRS, we used the same methods as previously described [3], measuring pain with ANI (instant value) and BPS before, during, and $5 \mathrm{~min}$ after the dressing change of a central venous catheter. Our hypothesis was that this procedure was painful. This study was approved by the ethics committee: Comité-de-Protection-des-Personnes (CPP) Sud-Méditerranée-IV (NID-RCB:2014A00337-40). The characteristics of the 20 patients were median age 68 [inter-quartile range 54-73] years, $n=10$ (50\%) female, $n=9$ (45\%) medical admissions, Simplified Acute Physiological Score II 40 [34-47], and Sequential Organ Failure Assessment score 6 [2-9]; only three patients were mechanically ventilated and none were receiving vasopressors. The main findings supported our hypothesis (Fig. 1): the NRS significantly increased from $0.0[0.0-4.0]$ at baseline before the procedure to 4.5 [3.8-5.0] during the procedure $(p<0.001)$, as did the BPS score [from $3.0(3.0-3.0)$ to $3.5(3.0-4.0) ; p<0.01$ ], while ANI decreased significantly from 68.5 [54.8-83.0] to 42.0 [35.8-59.3] ( $p=0.001$, Mann-Whitney-Wilcoxon tests). Among the 13 patients who had no or only light pain before the procedure, $8(62 \%)$ experienced moderate pain during the procedure (NRS 4-5). Pain was described by patients as stinging/burning. Our investigations found that the nursing procedure had been modified from our first study because the hygiene department now recommends using alcoholic chlorhexidine instead of non-alcoholic povidone-iodine (PVI) for catheter dressing changes. Another publication showed that the BPS score "unexpectedly" increased from $3.5( \pm 0.7)$ to 5.0 $( \pm 1.0)$ during a catheter dressing change in 36 mechanically ventilated ICU patients [5]. Alcoholic PVI was used (author's information). Many other factors could also be associated with pain (e.g. patient population, analgesia practices, nursing procedure). 


\section{MAX \\ pain}

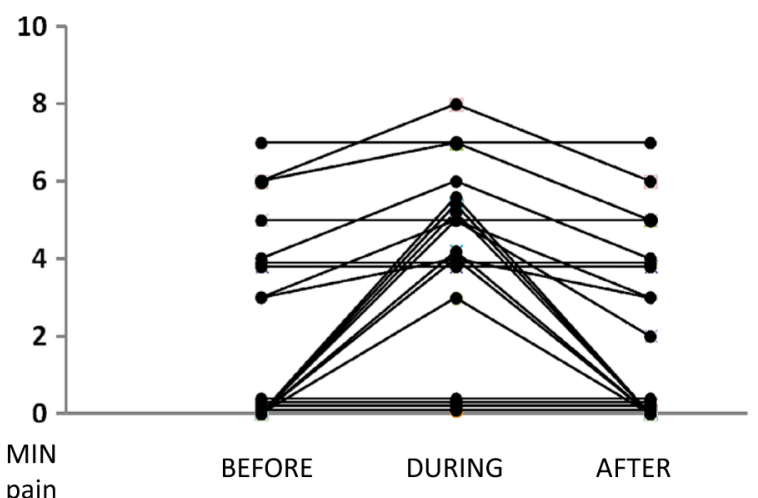

pain

B BEHAVIOURAL PAIN SCALE (INVESTIGATOR'S MEASUREMENT)

MAX

pain

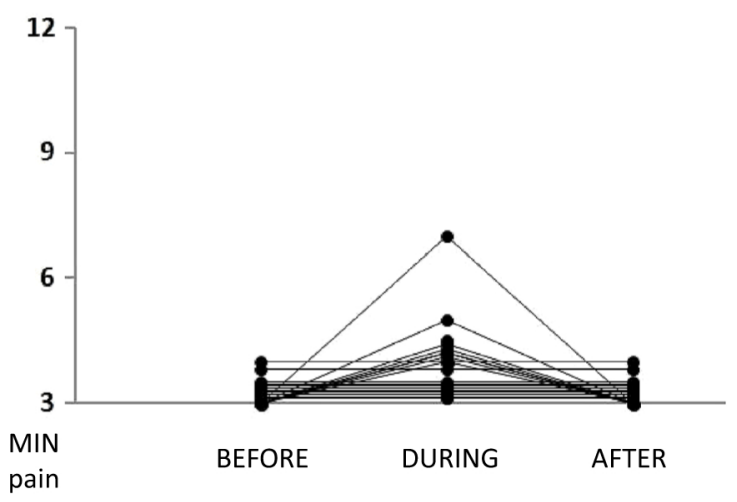

MIN

pain

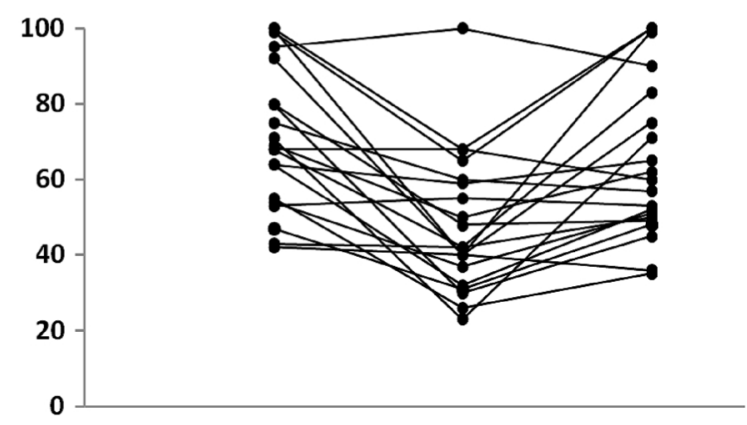

4

Fig. 1 Individual measurements of NRS, BPS, and ANI before, during, and after a catheter dressing change. This figure shows the individual measurements obtained in the 20 patients included for analysis with each of the three pain assessment tools according to different situations: before, during, and 5-min after a dressing change of a central venous catheter. The timing of measurements was strictly monitored by the research team, as previously described in detail [3]. Using the same methods, the maximal BPS and NRS values were recorded during the procedure. For $\mathrm{ANI}$, the minimal value was determined by an independent analysis of ANI data recordings [3]. NRS (from $0=$ "no pain"to $10=$ "maximal pain") and BPS (from $3=$ "no pain" to $12=$ "maximal pain") significantly increased during the procedure, indicating an increase in self-reported (Fig. 1a) and behavioural pain intensities (Fig. 1b), respectively, while ANI (from $100=$ "no pain" to $0=$ "maximal pain") significantly decreased (Fig. 1C), indicating a decrease in parasympathetic/sympathetic balance (i.e. an increased sympathetic tone, suggesting an increased physiological stress response). Note that changes in BPS are less frequent and much lower than changes in NRS. This has already been reported in ICU patients able to communicate, suggesting that NRS is the gold standard for pain measurement if the patients are able to communicate [1]. NRS 0-10 numeric rating scale, BPS behavioural pain scale, ANI analgesia nociception index

In conclusion, while many painful ICU procedures have been well recognised (e.g. turning, tracheal aspiration) $[2,3]$, many remain under-investigated and so probably under-treated. Even "a priori" non-painful procedures can be significantly painful for ICU patients. For pain tool validation studies in non-communicant patients, only non-physical or very gentle physical stimulations should be recommended as the reference non-painful procedure (e.g. performing a Richmond Agitation Assessment Scale measurement [4]).

\section{Author details}

1 Department of Anaesthesia and Critical Care Medicine, University of Montpellier Saint Eloi Hospital, 34295 Montpellier Cedex 5, France. ${ }^{2}$ PhyMedExp, INSERM U1046, CNRS, UMR 9214, University of Montpellier, 34295 Montpellier Cedex 5 , France. ${ }^{3}$ Department of Statistics, University of Montpellier La Colombière Hospital, 34295 Montpellier Cedex 5, France.

\section{Funding}

Support for this study was provided solely via institutional and/or departmental sources (Montpellier University Hospitals; 34000, France). 


\section{Compliance with ethical standards}

\section{Conflicts of interest}

In contexts unrelated to the present work, Prof. Jaber has consulted for and received honorarium from the following companies: Dräger, Hamilton, Maquet and Fisher Paykel. No other conflicts of interest related to this article exist for the other authors.

\section{References}

1. Puntillo K, Gelinas C, Chanques G (2017) Next steps in ICU pain research. Intensive Care Med 43:1386-1388

2. Chanques $G$, Payen JF, Mercier G, de Lattre S, Viel E, Jung B, Cissé M, Lefrant JY, Jaber S (2009) Assessing pain in non-intubated critically ill patients unable to self report: an adaptation of the behavioral pain scale. Intensive Care Med 35:2060-2067

3. Chanques G, Tarri T, Ride A, Prades A, De Jong A, Carr J, Molinari N, Jaber S (2017) Analgesia nociception index for the assessment of pain in critically ill patients: a diagnostic accuracy study. Br J Anaesth 119:812-820

4. Chanques G, Garnier O, Carr J, Conseil M, de Jong A, Rowan CM, Ely EW, Jaber S (2017) The CAM-ICU has now a French "official" version. The translation process of the 2014 updated Complete Training Manual of the Confusion Assessment Method for the Intensive Care Unit in French (CAM-ICU.fr). Anaesth Crit Care Pain Med 36:297-300

5. Ayasrah S (2016) Care-related pain in critically ill mechanically ventilated patients. Anaesth Intensive Care 44:458-465 